\title{
Expanding a Comprehensive Strategy for Overdose Prevention in the USA
}

\author{
David Vlahov
}

Published online: 5 June 2019

(C) The New York Academy of Medicine 2019

The Centers for Disease Control (CDC) reported 72,237 deaths due to drug overdose in 2017 [1]. This count in 2017 was higher than the number of deaths related to firearms, motor vehicle crashes, or HIV/AIDS in any single year. While the count was nearly 10\% higher in 2017 than 2016, an October 2018 report from the CDC noted a $2.3 \%$ drop in the prior 6 months compared to the previous 6 months [2]. The data are provisional and need to be interpreted with caution. While this observation may be seen as encouraging, the count remains high.

The response to the overdose crisis has included policy initiatives at the local, state, and federal levels. The federal has officially declared an opioid crisis public health emergency. A number of states have declared overdoses as public health emergencies to implement new guidelines for prescribing opiates, expanding access to naloxone which reverses opioid overdoses, and expanding drug treatment options. City and country health departments and community agencies have organized local initiatives. More needs to be done [3].

An approach that has been used outside of the USA is what some have named overdose prevention sites (OPS) and others call supervised consumption spaces (SCS) or safer injection facilities (SIF). These sites provide space for people to consume pre-obtained drugs in controlled settings under the supervision of trained staff with access to sterile injection equipment and naloxone or

D. Vlahov $(\bowtie)$

Yale School of Nursing, Orange, CT, USA

e-mail: David.Vlahov@yale.edu oxygen. Some sites also offer or provide active referral to health care, medication-assisted therapy, and social services. The programs are not stand-alone in design or practice but are considered and treated as part of a comprehensive approach to public health prevention of overdose mortality and blood-borne infections such as HIV and hepatitis.

Evidence for the effectiveness for such programs is not available in the USA because no officially sanctioned program has been implemented as of this writing, although one unsanctioned site opened in 2014 [4]. Data are available from programs outside the USA and the one unsanctioned pilot site in the USA. Over 70 studies, mostly from Canada and Australia, reported that these programs attracted the most marginalized persons who inject drugs, promoted safer injection conditions, enhanced access to primary health care, and prevented overdose deaths. These programs were not found to increase drug injecting, drug trafficking or crime in the surrounding environments, and were found to be associated with reduced levels of public drug injections and discarded syringes [5].

Despite evidence of benefit from the international literature, there are legal and social impediments to opening these programs in the USA. The federal Controlled Substances Act can be interpreted to bar such programs, i.e., section 844 prohibits drug possession which would affect every participant attending a program. Another federal statute codified in 21 USC $\S 856$ makes it a felony to knowingly open, lease, rent, use, or maintain any place for the 
purpose of manufacturing, distributing, or using any controlled substance. Legal scholars are arguing that is should not apply to OPS because the statute was not intended to thwart a public health intervention. Yet there is clear legal authority for states to authorize such programs just as they have for cultivation, distribution, and possession of medical marijuana. Yet states that authorize such programs cannot nullify federal law and so cannot protect a program from being shut down.

Deliberations on the tradeoffs for opening programs include levels of acceptance and support for these initiatives which includes the degree to which people who use drugs would support and use such programs. Likewise, testing the level of public resistance or acceptance and support for such programs is an important influencer for the political discourse. In this issue of the journal, two reports address these issues. Park and colleagues interviewed 326 people who use opiates in three cities and more than three quarters would be willing to use such programs but expressed concerns about arrest and privacy [6]. Roth and colleagues interviewed 360 residents and 79 business owners or staff in a neighborhood within Philadelphia that had the highest rates of overdose deaths; $90 \%$ and $63 \%$ were supportive, respectively [7]. These data contribute to the ongoing conversation about opening such programs in areas that are the most highly affected by the overdose crisis.

\section{References}

1. Hedegaard H, Miniño AM, Warner M. Drug overdose deaths in the United States, 1999-2017. NCHS Data Brief, no 329. Hyattsville, MD: National Center for Health Statistics. 2018. Available from: https://www. cdc.gov/nchs/products/databriefs/db329.htm Accessed: May 2, 2019.

2. Ahmad FB, Escobedo LA, Rossen LM, Spencer MR, Warner M, Sutton P. Provisional drug overdose death counts. National Center for Health Statistics. 2019. https://www.cdc. gov/nchs/nvss/vsrr/drug-overdose-data.htm. Accessed: May 2, 2019

3. Saloner B, McGinty EE, Beletsky L, Buthenthal R, Beyrer C, Botticelli M, et al. A public health strategy for the opioid crisis. Public Health Rep. 2018;133(Supp 1):24S-34.

4. Kral AH, Davidson PJ. Addressing the nation's opioid epidemic: lessons from an unsanctioned supervised injection site in the U.S. Am J Prev Med. 2017;53(6):919-22.

5. Potier C, Laprevote V, Dubois-Arber F, Cottencin O, Rolland B. Supervised injection services: what has been demonstrated? A systematic literature review. Drug Alcohol Depend. 2014;145:48-68.

6. Park JY, Sherman SG, Rouhani S, Morales KB, McKenzie M, Allen ST, et al. Willingness to use safer consumption spaces among opioid users at high risk of fentanyl overdose in Baltimore, Providence and Boston. J Urban Health. 2019;96

7. Roth A, Kral AH, Mitchell A, Mukherjee R, Davidson P, Lankenau S. Overdose prevention site acceptability among residents and businesses surrounding a proposed site in Philadelphia, USA. J Urban Health. 2019;96

Publisher's Note Springer Nature remains neutral with regard to jurisdictional claims in published maps and institutional affiliations. 